\title{
Analisis Injeksi Daya Reaktif Untuk Memperbaiki Faktor Daya Pada Line Instalasi Listrik Gedung Workshop AK-Manufaktur Bantaeng
}

\author{
Hermansyah \\ Akademi Komunitas Industri Manufaktur Bantaeng, Bantaeng, Sulawesi Selatan, Indonesia \\ anchaogi.hp@gmail.com
}

\begin{abstract}
This research is a case study, namely the electrical installation system for AK-Manufacturing Bantaeng fabrication workshops. This study aims to improve the value of $\cos \varphi$ (power factor) from 0.75 to 0.97 and to determine the capacity of the capacitor bank that will be installed on the electrical installation line of the AK-Manufacturing Bantaeng Fabrication Machine workshop building. The problem that occurs is the low value of cos $\varphi$ (power factor) in the installed electrical system which causes the installed active power to be not maximal. For this reason, a capacitor bank with an adjusted capacity value is needed to provide reactive power injection so that the value of cos $\varphi$ can be increased from 0.75 to 0.97. This study uses an analysis method to determine the value of reactive power to be injected into the electrical installation system. The results of this study indicate that the required reactive power injection capacity is $12 \mathrm{KVar}$ or 12,000 Var. This value is sufficient to improve the power factor from 0.75 to 0.97 . This means that the electrical installation system is more optimal.
\end{abstract}

Keywords-Power Factor, Capacitor Bank, Reactive Power, Case Study.

Intisari-Penelitian ini merupakan penelitian study kasus yaitu pada sistem instalasi listrik workshop mesin fabrikasi AK-Manufaktur Bantaeng. Penelitian ini bertujuan untuk memperbaiki nilai $\cos \varphi$ (factor daya) dari 0.75 menjadi 0.97 dan untuk mengetahui kapasitas kapasitor bank yang akan dipasang pada line instalasi listrik gedung workshop Mesin Fabrikasi AK-Manufaktur Bantaeng. Permasalahan yang terjadi adalah rendahnya nilai $\cos \varphi$ (factor daya) pada system kelistrikan yang terpasang sehingga menyebabkan tidak maksimalnya daya aktif yang terpasang. Untuk itu dibutuhkan kapasitor bank dengan nilai kapasitas yang telah disesuaikan untuk memberikan injeksi daya reaktif sehingga nilai $\cos \varphi$ dapat dinaikkan dari 0.75 hingga 0.97. Penelitian ini menggunakan metode analisis untuk menentukan nilai daya reaktif yang akan diinjeksikan ke dalam system instalasi listrik. Hasil dari penelitian ini menunjukkan bahwa kapasitas injeksi daya reaktif yang dibutuhkan sebesar 12 KVar atau 12.000 Var. Nilai tersebut cukup untuk memperbaiki faktor daya dari 0.75 menjadi 0.97. Artinya sistem instalasi listrik tersebut lebih optimal.

Kata Kunci-Faktor Daya, Kapasitor Bank, Daya Reaktif, Study Kasus.

\section{PENDAHULUAN}

Listrik merupakan kebutuhan utama aktivitas rumah tangga dan instansi pemerintah dan industri. Distribusi daya listrik yang handal dapat menpengaruhi kelancaran aktifitas kegiatan produksi khususnya di industri dan tempat pelatihan yang membutuhkan daya listrik yang stabil dalam rangka mengoperasikan mesin yang menyerap daya yang besar.

Gedung Workshop Mesin Fabrikasi AK-Manufaktur Bantaeng merupakan salah satu sarana prasarana untuk menunjang kegiatan praktikum mahasiswa Program Studi Teknik Perawatan Mesin AK-Manufaktur Bantaeng. Gedung workshop tersebut, didalamya terdapat 3unit mesin bubut, 4unit mesin frais, 2 unit mesin CNC, 4 unit mesin gerinda, 2 buah mesin bor, 1 buah mesin asah pahat, dan 17 unit mesin las.

Tentunya mesin-mesin tersebut menyerap daya reaktif yang tidak sedikit sehingga menyebabkan tidak maksimalnya daya aktif terpasang di panel induk. Hal tersebut disebabkan oleh $\operatorname{Cos} \varphi$ total pada mesin-mesin tersebut berada pada angka $<0.85$ Hal tersebut merupakan masalah yang serius bagi industri dan harus mendapatkan perhatian khusus dalam rangka meningkatkan nilai $\operatorname{Cos} \varphi$ total ke angka yang mendekati 1. Solusi permasalahan tersebut adalah dengan memasang kapasitor bank yang berfungsi memberikan injeksi daya reaktif kepada beban sehingga nilai faktor daya $(\cos \varphi)$ dapat dinaikkan mendekati angka 1.

Penelitian ini bertujuan untuk memperbaiki nilai $\cos \varphi$ (factor daya) dari 0.75 hingga mendekati angka 1 yaitu 0.97. Selain itu penelitian ini juga bertujuan untuk mengetahui kapasitas kapasitor bank yang akan dipasang pada line instalasi listrik gedung workshop Mesin Fabrikasi AK-Manufaktur Bantaeng.

\section{LANDASAN TEORI}

\section{A. Beban pada Sistem Tenaga Listrik}

Sistem tenaga listrik adalah serangkaian peralatanperalatan kelistrikan yang saling bekerjasama satu sama lain dalam menyalurkan tenaga listrik mulai dari system pembangkitan, transformator, jaringan transmisi, garudu induk, jaringan distribusi, alat-alat proteksi dan beban.

Dalam rangkaian listrik $\mathrm{AC}$, beban terbagi menjadi tiga jenis yaitu beban resistif, beban kapasitif dan beban induktif.

\section{Beban Resistif.}

Beban resistif dihasilkan oleh komponen-komponen kelistrikan yang memiliki tahanan murni seperti pada lampu pijar dan berbagai macam elemen pemanas. Beban jenis ini bersifat pasif yaitu tidak mampu untuk menghasilkan energy listrik. Beban jenis ini tidak menyerap daya reaktif melainkan beban jenis ini hanya 
menyerap daya aktif. Arus dan tengangan pada beban resistif akan sefasa atau tidak akan menimbulkan pergeseran sudut fasa. Dengan kata lain factor daya pada jenis beban ini adalah 1 yang dinotasikan $\operatorname{Cos} \varphi$. Berikut ini adalah persamaan untuk menentukan daya aktif pada beban resistif (Nur, 2017).

$$
\begin{gathered}
P=V . I \\
P=\sqrt{ } 3 . V . I
\end{gathered}
$$

\section{Beban Induktif}

Beban Induktif adalah beban yang terdiri dari kumparan kawat yang dililitkan pada suatu inti. Contoh jenis beban ini adalah inductor, solenoid, motor listrik 1 fhasa dan 3 fhasa, transformator 1 fhasa dan 3 fhasa dll. Jenis beban ini dapat memberikan dampak pergeseran sudut fasa pada arus sehingga mengakibatkan arus tertinggal terhadap tegangan (lagging). Jenis beban ini menyerap dua jenis daya, yaitu daya aktif dan daya reaktif. Berikut ini adalah persamaan untuk menentukan daya aktif. [6]

$$
\begin{aligned}
& \mathrm{P}=\mathrm{V} . \mathrm{I} . \operatorname{Cos} \varphi \\
& \mathrm{P}=\sqrt{ } 3 . \mathrm{V} . \mathrm{I} . \operatorname{Cos} \varphi
\end{aligned}
$$

\section{Beban Kapasitif}

Beban jenis kapasitif memiliki kelebihan yang mampu menyimpan energy listrik yang berasal dari pengisian elektrik pada suatu rangkaian listrik. Jenis beban ini menyebabkan arus mendahului tegangan atau biasa disebut dengan istilah (leading). Jenis beban ini menyerap daya aktif dan dapat mengeluarkan daya reaktif sehingga sangat cocok digunakan dalam injeksi daya reaktif pada beban-beban induktif yang pada dasarnya membutuhkan daya reaktif untuk bekerja sehingga daya aktif yang disuplay oleh PT.PLN (persero) dapat dimaksimalkan. Berikut ini adalah persamaan untuk menentukan daya reaktif. [6]

$$
\begin{aligned}
& \mathrm{Q}=\mathrm{V} . \mathrm{I} \cdot \operatorname{Sin} \varphi \\
& \mathrm{Q}=\sqrt{ } 3 . \mathrm{V} \cdot \mathrm{I} \cdot \operatorname{Sin} \varphi
\end{aligned}
$$

\section{B. Faktor Daya}

Faktor daya merupakan salah satu indikator baik buruknya kualitas daya listrik. Faktor daya atau faktor kerja adalah perbandingan antara daya aktif (Watt) dengan daya semu/daya total (VA), atau cosinus sudut antara daya aktif dan daya semu/daya total. Peningkatan daya reaktif akan meningkatkan sudut antara daya aktif dan daya semu sehingga dengan daya aktif yang tetap akan mengakibatkan peningkatan daya semu yang akan dikirimkan. Nilai faktor daya tertinggi adalah 1. Sistem dengan faktor daya seperti ini memiliki efisiensi yang sangat baik dimana hal ini berarti daya total/semu (VA) yang dibangkitkan digunakan secara utuh pada beban resistif (Watt). Dalam hal ini nilai daya total/ semu (VA) sama dengan daya aktif (Watt). [3]

Pada suatu sistem tenaga listrik memiliki 3 jenis faktor daya yaitu faktor daya unity, faktor daya mendahului (leading) dan faktor daya terbelakang (lagging) yang ditentukan oleh jenis beban pada sistem tenaga listrik.

Perbaikan faktor daya untuk memperbesar harga $\cos \varphi$ (pf) yang rendah, hal yang mudah di lakukan adalah dengan cara mempersempit sudut phi 1 sehhingga menjadi phi 2 berarti phi $1>$ phi 2 . Usaha untuk memperkecil sudut phi itu hal yang mungkin dilakukan adalah memperkecil komponen daya reaktif (VAR) Komponen daya rekatif yang bersifat rinduktif harus dikurangi dan pengurangan tersebut dilakukan dengan menambah suatu sumber daya rekatif yaitu berupa kapasitor atau lebih dikenal dengan istilah kapasitir bank.

\section{Kapasitor Bank}

Kapasitor bank merupakan komponen kelistrikan yang berfungsi untuk meningkatkan power faktor (pf). Kapasitor bank terdiri dari rangkaian-rangkaian kapasitor yang saling terhubung satu sama lain baik secara hubung seri maupun secara parallel yang dirangkai kedalam satu panel kapasitor bank. [3]

Kapsitor bank sangat dibutuhkan oleh industri dan institusi pendidikan yang didalamnya terdapat banyak beban induktif. Jika factor daya pada sebuah industri dibawah 0.85 maka industri tersebut akan dikenakan denda oleh PLN. Untuk mendapatkan factor daya $>85$ maka suatu industri harus memasang kapasitor bank pada instalasi kelistrikannya.

\section{Perbaikan Faktor Daya}

Secara umum perbaikan factor daya adalah dengan menambahkan komponen sebagai pembangkit daya reaktif yaitu kapasitor bank. Kapasitor bank tersebut berfungsi untuk mensuplai kebutuhan daya reaktif dalam satuan Var pada beban-beban induktif. Untuk merencanakan suatu sistem dalam memperbaiki faktor daya, dapat dipergunakan suatu konsep yaitu kompensator ideal, dimana sistem ini dapat dihubungkan pada titik penyambungan secara paralel dengan beban dan memenuhi 3 fungsi utama, yaitu memperbaiki faktor daya mendekati nilai 1 (unity power factor), mengurangi atau mengeliminasi regulasi tegangan dan menyeimbangkan arus beban dan tegangan fasa. Untuk memenuhi kebutuhan daya reaktif yang efektif dan efisien, maka perlu dilakukan pemilihan sumber daya reaktif untuk perbaikan faktor daya. [1]

\section{METODE PENELITIAN}

Penelitian ini terbagi kedalam beberapa tahap yaitu:

1. Melakukan study literature dan melakukan pengukuran nilai $\operatorname{Cos} \varphi$ total pada mesin-mesin yang ada di workshop mesin.

2. Melakukan analisis data dengan menentukan kapasitas kebutuhan kapasitor bank untuk memperbaiki faktor daya $(\operatorname{Cos} \varphi)$ pada instalasi listrik gedung workshop mesin.

3. Memastikan rancangan kapasitor bank sesuai dengan standard dan peraturan yang berlaku.

Tahapan penelitian ini ditampilkan secara detail pada Gambar 1 berikut ini: 


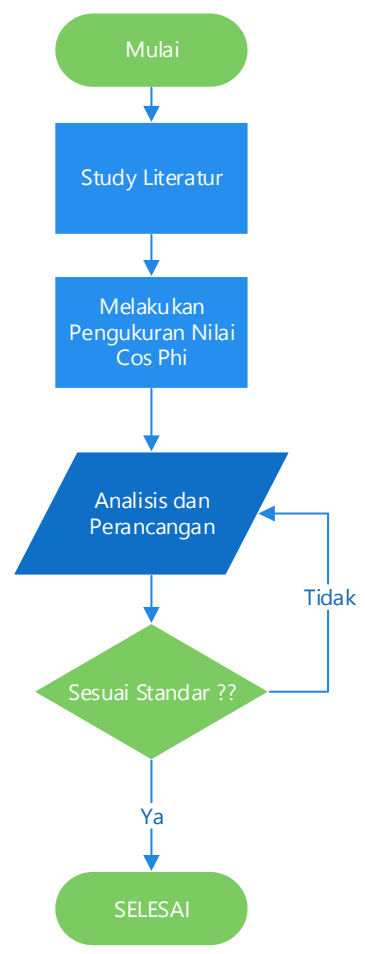

Gambar.1 Flow Chart Penelitian

\section{HASIL DAN PEMBAHASAN}

Dari hasil obeservasi (data name plate) dan pengukuran secara langsung diketahui parameter mesinmesin fabrikasi di workshop mesin yaitu sebagai berikut:

1. Total daya aktif pada mesin-mesin fabrikasi adalah $28.19 \mathrm{KW}$.

2. $\operatorname{Cos} \varphi$ total yang didapatkan dari hasil perhitungan adalah 0.75 .

3. $\operatorname{Cos} \varphi$ total yang didapatkan dari hasil pengukuran adalah 0.76 .

4. Tegangan terukur pada L-L 385 Volt

5. Tegangan terukur pada L-N 225 Volt

Data tersebut merupakan data awal untuk menentukan kapasitas kapasitor bank. Dari data tersebut maka daya reaktif dapat dihitung dengan menggunakan persamaan berikut in:

$$
\mathrm{Q}=\sqrt{ } 3 \times \mathrm{V} \times \mathrm{I} \times \operatorname{Sin} \varphi
$$

Dengan demikian besarnya daya reaktif (Q) pada mesin-mesin fabrikasi yang ada pada Table.1 adalah sebagai berikut:

- Mesin las besar

$$
\begin{aligned}
\mathrm{Q} & =\sqrt{ } 3 \times 380 \times 32 \times \operatorname{Sin} \varphi \\
& =1051 \times 2 \text { (unit) } \\
& =2102 \mathrm{Var}
\end{aligned}
$$

- Mesin las kecil

$$
\mathrm{Q} \quad=\sqrt{3} \times 380 \times 16 \times \operatorname{Sin} \varphi
$$$$
=526 \times 15 \text { (unit) }
$$$$
=7890 \mathrm{Var}
$$

- Mesin gerinda

$$
\begin{aligned}
\mathrm{Q} & =\sqrt{3} \times 380 \times 2.8 \times \operatorname{Sin} \varphi \\
& =92 \times 4 \text { (unit) } \\
& =368 \text { Var }
\end{aligned}
$$

- Mesin Asah Pahat

$$
\begin{aligned}
\mathrm{Q} & =\sqrt{ } 3 \times 380 \times 4 \times \operatorname{Sin} \varphi \\
& =131 \times 1 \text { (unit) } \\
& =131 \mathrm{Var}
\end{aligned}
$$

- Mesin Bor

\begin{tabular}{|c|c|c|c|c|}
\hline $\begin{array}{l}\mathbf{N} \\
\mathbf{0}\end{array}$ & $\begin{array}{l}\text { Mesin-Mesin } \\
\text { Fabrikasi }\end{array}$ & $\begin{array}{l}\text { Jumlah } \\
\text { Unit }\end{array}$ & $\begin{array}{c}\text { Total Daya } \\
\text { Aktif } \\
\text { (Watt) }\end{array}$ & $\begin{array}{c}\text { Total Daya } \\
\text { Reaktif } \\
\text { (Var) }\end{array}$ \\
\hline 1 & Mesin Las Besar & 2 & 25600 & 2102 \\
\hline 2 & Mesin Las Kecil & 15 & 96000 & 7890 \\
\hline 3 & Mesin Gerinda & 4 & 8800 & 368 \\
\hline 4 & Mesin Asah Pahat & 1 & 550 & 131 \\
\hline 5 & Mesin Bor & 2 & 520 & 198 \\
\hline 6 & Mesin CNC & 2 & 50000 & 10452 \\
\hline 7 & Mesin Frais & 4 & 12000 & 2.892 \\
\hline 8 & Mesin Bubut & 3 & 3500 & 828 \\
\hline \multicolumn{3}{|c|}{ Total } & 281930 & 24861 \\
\hline \multicolumn{5}{|c|}{$\begin{array}{lll}\text { Total Daya Aktif }: \mathbf{2 8 . 1 9} & \text { KWatt } \\
\text { Total Daya Reaktif }: \mathbf{2 4 . 8} \quad \text { KVar }\end{array}$} \\
\hline
\end{tabular}

$$
\begin{aligned}
\mathrm{Q} & =\sqrt{ } 3 \times 380 \times 3 \times \operatorname{Sin} \varphi \\
& =99 \times 2 \text { (unit) } \\
& =198 \mathrm{Var}
\end{aligned}
$$

- $\quad$ Mesin CNC

$$
\begin{aligned}
\mathrm{Q} & =\sqrt{ } 3 \times 380 \times 159 \times \operatorname{Sin} \varphi \\
& =5.226,33 \times 2 \text { (unit) } \\
& =10.452,66 \mathrm{Var}
\end{aligned}
$$

- Mesin Frais

$$
\begin{aligned}
\mathrm{Q} & =\sqrt{ } 3 \times 380 \times 22 \times \operatorname{Sin} \varphi \\
& =723,14 \times 4 \text { (unit) } \\
& =2.892,56 \mathrm{Var}
\end{aligned}
$$

- Mesin Bubut

$$
\begin{aligned}
\mathrm{Q} & =\sqrt{ } 3 \times 380 \times 8.4 \times \operatorname{Sin} \varphi \\
& =276,10 \times 3 \text { (unit) } \\
& =828,3 \mathrm{Var}
\end{aligned}
$$

Tabel.1

Data total daya aktif dan daya reaktif beban workshop mesin AK-Manufaktur Bantaeng.

Dari data perhitungan dan pengukuran, maka nilai kapasitas kapasitor bank untuk injeksi daya reaktif ke system line instalasi listrik gedung workshop mesin AKManufaktur Bantaeng dapat ditentukan dengan cara sebagai berikut:

- Faktor daya sebelum diperbaiki:

$\operatorname{Cos} \varphi \mathrm{Q} 1=0.75$

$\operatorname{Cos}^{-1}(0.75)=41.40$

Sin Q1 (41.40) = 0.66

- Faktor daya sesudah diperbaiki:

$\operatorname{Cos} \varphi \mathrm{Q} 2=0.97$

$\operatorname{Cos}^{-1}(0.97)=14.06$

Sin Q2 (14.06) = 0.24

- $\quad$ KVAR sebelum diperbaiki:

P (Kwatt) x Sin Q1

$28.19 \times 0.66=18.60 \mathrm{Kvar}$

- $\quad$ KVAR sesudah diperbaiki:

P (Kwatt) x Sin Q2

$28.19 \times 0.24=6.76 \mathrm{Kvar}$

Jadi kapasitas injeksi daya reaktif yang dibutuhkan untuk memperbaiki factor daya $\operatorname{Cos} \varphi$ dari 0.75 menjadi 0.97 pada line instalasi listrik gedung workshop mesin fabrikasi AK-Manufaktur Bantaeng adalah 18.60 Kvar - 
6.76 Kvar = 11.84 Kvar. Untuk itu kapasitor bank yang direkomendasikan adalah kapasitor yang berkapasitas $\mathbf{1 2}$ KVar 220/380 Volt.

\section{KESIMPULAN}

Line instalasi listrik gedung workshop mesin fabrikasi AK-Manufaktur Bantaeng membutuhkan injeksi daya reaktif sebesar $11.84 \mathrm{KVar}$. Untuk itu digunakan kapasitor bank yang berkapasitas 12 KVar 220/380 Volt. Perbaikan factor daya dapat memaksimalkan daya aktif terpasang secara keseluruhan. Faktor daya $(\cos \varphi)$ dapat diperbaiki dari 0.75 menjadi 0.97

\section{UCAPAN TERIMA KASIH}

Terlaksananya penelitian ini tidak terlepas dari berbagai pihak yang mendukung. Oleh karena itu penulis mengucapkan terima kasih kepada:

1. Para pimpinan Akademi Komunitas Industri Manufaktur Bantantaeng yang telah memberikan fasilitas dalam mendukung terlaksananya penelitian ini.

2. Teknisi Akademi Komunitas Industri Manufaktur Bantaeng yang telah banyak membantu dalam proses pengukuran dan pengambilan data awal.

3. Kepada dewan redaksi jurnal yang telah meluangkan waktu untuk bekerja secara maksimal sampai pada prses penerbitan.

\section{REFERENSI}

[1] Alland, Arfah, Perancangan Kebutuhan Kapasitor Bank Untuk Perbaikan Faktor Daya Pada Line Mess I di PT.Bumi Lamongan Sejati (WBL). Universitas Negeri Surabaya. 2017

[2] Ananta, Isdiyarto, Rancang Bangun Kapasitor Bank Untuk Efisiensi Daya Listrik Pada Industri Kecil. Journal Sainteknol, 2014, Vol.12 No 1.

[3] Ardiansyah, Haimi, Pengaruh Penggunaan Kapasitor Bank pada Penyulang Kota di PT. PLN5 (Persero) Rayon Meulaboh Kota. VOCATECH: Vocational Education and Technology Journal. Vol 2 hal. 21-28. 2020

[4] Aripriharta, Mardianto, Amri, Muharnis. Rancang Bangun Simulator Perbaikan Faktor Daya Listrik Sebagai Modul Praktikum di Laboratorium Elektrika Daya. Jurnal INOVTEK, Vol.2, No.2 2020

[5] Dugan, R.C, Granaghan, M. F, Beaty H. Wayne, Electrical Power System Quality, McGraw-Hill. 1996

[6] Nur, Hardiranto, Analisa optimasi perbaikan faktor daya dan drop tegangan dengan menggunakan kapasitor bank pada line 5 PT. Bukit Asam (persero) Tbk. Fakultas teknik: Universitas Lampung. 2017

[7] Jumadi, Tambunan. Analisis Pengaruh Jenis Beban Listrik Terhadap Kinerja Pemutus Daya Listrik Di Gedung Cyber Jakarta. Jurnal Energy \& Kelistrikan Vol.7 No.2. 2015

[8] Prasetyo, Assafat. Efektifitas Pemasangan Kapasitor Sebagai Metode Alternatif Penghemat Energi Listrik. Media Elektrika, Vol.3, Vo.2, 2010

[9] Ulya, Analisis dan Simulasi Pengaruh Pemasangan Kapasitor Bank Untuk Perbaikan Faktor Daya Menggunakan Simulink pada Sistem Tenaga Listrik di PT. Bogowonto Prima laras. Media Elektrika, Vol.12, No.1, 2019
[10] Yani, Pemasangan Kapasitor Bank Untuk Perbaikan Faktor Daya. Journal of Electrical Technology, Vol.2, No.3. 2017 